\title{
Favipiravir versus Arbidol for COVID-19: A Randomized Clinical
}

\section{Trial}

Chang Chen, $\mathrm{MD}^{1,2, \#}$, Yi Zhang, $\mathrm{PhD}^{3,4, \#, ~ J i a n y i n g ~ H u a n g, ~} \mathrm{MD}^{1,5, \#}$, Ping Yin, $\mathrm{PhD}^{6, \#}$, Zhenshun Cheng, $\mathrm{MD}^{7}$, Jianyuan $\mathrm{Wu}, \mathrm{PhD}^{1,3}$, Song Chen, $\mathrm{MD}^{8}$, Yongxi Zhang, $\mathrm{MD}^{9}$, Bo Chen, $\mathrm{PhD}^{1,3}$, Mengxin $\mathrm{Lu}, \mathrm{MD}^{8}$, Yongwen Luo, $\mathrm{MD}^{8}$, Lingao $\mathrm{Ju}, \mathrm{MD}^{8}$, Jingyi Zhang, $\mathrm{MD}^{10}$, Xinghuan Wang, $\mathrm{MD}, \mathrm{PhD}^{1,3,5,11, *}$

\section{Author affiliations:}

${ }^{1}$ Clinical Trial Center, Zhongnan Hospital of Wuhan University, Wuhan, Hubei, 430071, China

${ }^{2}$ Department of Anesthesiology, Zhongnan Hospital of Wuhan University, Wuhan, Hubei, 430071, China

${ }^{3}$ Center for Life Sciences, Peking University, Beijing, 100871, China

${ }^{4}$ Euler Technology, ZGC Life Sciences Park, Beijing, 102200, China

${ }^{5}$ Wuhan Leishenshan Hospital, Wuhan, Hubei, 430000, China

${ }^{6}$ Department of Epidemiology and Biostatistics, School of Public Health, Tongji Medical College, Huazhong University of Science and Technology, Wuhan, Hubei, 430030, China

${ }^{7}$ Department of Respiratory Medicine, Zhongnan Hospital of Wuhan University, Wuhan, Hubei, 430071, China

${ }^{8}$ Department of Urology, Zhongnan Hospital of Wuhan University, Wuhan, Hubei, 430071, China

${ }^{9}$ Department of Infectious Diseases, Zhongnan Hospital of Wuhan University, Wuhan, Hubei, 430071, China 
medRxiv preprint doi: https://doi.org/10.1101/2020.03.17.20037432; this version posted April 15, 2020. The copyright holder for this preprint (which was not certified by peer review) is the author/funder, who has granted medRxiv a license to display the preprint in perpetuity. All rights reserved. No reuse allowed without permission.

${ }^{10}$ Department of Cardiology, The Third People's Hospital of Hubei Province, Wuhan, Hubei, 430033, China

${ }^{11}$ Center for Evidence-Based and Translational Medicine, Zhongnan Hospital of Wuhan University, Wuhan, Hubei, 430071, China

${ }^{\#}$ Contributed equally.

*Corresponding author: Dr. Xinghuan Wang, Clinical Trial Center, Zhongnan Hospital of Wuhan University, Wuhan, Hubei 430071, China. Tel: +86-27-67813104. E-mail: wangxinghuan@whu.edu.cn 


\section{Abstract}

\section{Background}

No clinically proven effective antiviral strategy exists for the epidemic Coronavirus Disease 2019 (COVID-19).

\section{Methods}

We conducted a prospective, randomized, controlled, open-label multicenter trial involving adult patients with COVID-19. Patients were randomly assigned in a 1:1 ratio to receive conventional therapy plus Umifenovir (Arbidol) $(200 \mathrm{mg} * 3 /$ day) or Favipiravir (1600mg*2/first day followed by $600 \mathrm{mg} * 2 /$ day) for 10 days. The primary outcome was clinical recovery rate of Day 7. Latency to relief for pyrexia and cough, the rate of auxiliary oxygen therapy (AOT) or noninvasive mechanical ventilation (NMV) were the secondary outcomes. Safety data were collected for 17 days.

\section{Results}

240 enrolled COVID-19 patients underwent randomization; 120 patients were assigned to receive Favipiravir (116 assessed), and 120 to receive Arbidol (120 assessed). Clinical recovery rate of Day 7 does not significantly differ between Favipiravir group (71/116) and Arbidol group (62/120) $(\mathrm{P}=0.1396$, difference of recovery rate: $0.0954 ; 95 \% \mathrm{CI}:-0.0305$ to 0.2213 ). Favipiravir led to shorter latencies to relief for both pyrexia (difference: 1.70 days, $\mathrm{P}<0.0001$ ) and cough (difference: 1.75 days, $\mathrm{P}<0.0001$ ). No difference was observed of AOT or NMV rate (both P>0.05). The most frequently observed Favipiravir-associated adverse event was raised serum uric acid (16/116, OR: 5.52, $\mathrm{P}=0.0014)$.

\section{Conclusions}

Among patients with COVID-19, Favipiravir, compared to Arbidol, did not significantly improve the clinically recovery rate at Day 7. Favipiravir significantly 
medRxiv preprint doi: https://doi.org/10.1101/2020.03.17.20037432; this version posted April 15, 2020. The copyright holder for this preprint (which was not certified by peer review) is the author/funder, who has granted medRxiv a license to display the preprint in perpetuity. All rights reserved. No reuse allowed without permission.

improved the latency to relief for pyrexia and cough. Adverse effects caused Favipiravir are mild and manageable. This trial is registered with Chictr.org.cn (ChiCTR2000030254). 


\section{Introduction}

The epidemic coronavirus disease 2019 (COVID-19) caused by SARS-CoV-2 started in Dec. 2019. As of Apr. 8, 2020, the WHO reported 1,452,178 confirmed cases across more than 130 countries with a global mortality rate of $5.8 \% .^{1,2}$

At the moment, no specific treatment exists for COVID-19. Standard practice of care focus on treating the clinical symptoms (pyrexia, cough, and acute respiratory distress syndromes (ARDS)) of patients with supportive care such as fluid management and auxiliary oxygen therapy. No proven clinical efficacy of antiviral agent for COVID-19 were reported, whilst some of them (Remdesivir, hINFa-2b, Ribavirin, Chloroquine and Arbidol) are currently under clinical trials for COVID-19.,

SARS-CoV-2 and influenza viruses exhibit similar disease presentations with similar organ trophism. Because both viruses are RNA virus depending on RNA-dependent RNA polymerase (RdRp) to replicate, the RdRp inhibitor Arbidol (common name for Umifenovir) approved for influenza in Russia and China has been proposed as a standard care option for COVID-19, mainly based on its mechanism-of-action (MoA) and its effects in treating influenza-associated pneumonia. ${ }^{5-7}$

Favipiravir, an antiviral drug targeting RdRP, ${ }^{8}$ approved in Japan for influenza, has an IC50 of 0.013-0.48 ug/ml for influenza A. Comparing this with the EC50 of 2.7-13.8 ug/ml of Arbidol, ${ }^{9}$ we consider Favipiravir might serve as a potential candidate to treat COVID-19. Specifically, we hypothesized that Favipiravir would be superior to Arbidol in terms of improving clinical recovery rate at Day 7, and alleviating pyrexia, cough, and ARDS. To evaluate the clinical efficacy and safety of Favipiravir versus 
medRxiv preprint doi: https://doi.org/10.1101/2020.03.17.20037432; this version posted April 15, 2020. The copyright holder for this preprint (which was not certified by peer review) is the author/funder, who has granted medRxiv a license to display the preprint in perpetuity. All rights reserved. No reuse allowed without permission.

Arbidol as treatment for COVID-19, we conducted a prospective, randomized, controlled, open-label multicenter trial, in adult patients with COVID-19. 


\section{Methods}

\section{Patients}

Patients were assessed for eligibility on the basis of: (1) aged 18 years or older; (2) voluntarily provided informed consent; (3) initial symptoms were within 12 days; (4) Diagnosed as COVID-19 pneumonia. According to the Chinese Diagnosis and Treatment Protocol for Novel Coronavirus Pneumonia at that moment, ${ }^{10,11}$ COVID-19 could be diagnosed without a positive SARS-CoV-2 nucleic acid test result by: (1) a positive chest CT scan; (2) significant clinical manifestation including pyrexia, cough, breath difficulty and other indications of viral infection of lower respiratory tract; and (3) laboratory results indicating lymphopenia and (optional) leukopenia. Hence, male and female adult patients with clinically confirmed COVID-19 including moderate, severe or critical types of COVID-19 were eligible. Patients were excluded if they meet any of following criteria: (1) allergic to Favipiravir or Arbidol; (2) with elevated ALT/AST (>6x upper limit of normal range) or with chronic liver disease (cirrhosis at grade Child-Pugh C); (3) severe/critical patients whose expected survival time were <48 hours; (4) female in pregnancy; (5) HIV infection; or (6) considered unsuitable by researchers for the patient's best interest. Written informed consents were obtained from all patients or their authorized representatives if the patient was unable to write physically.

\section{Study design}

The study was designed as a prospective, randomized, controlled, open-label 
multicenter trial (Figure 1) conducted from Feb. 20 to Mar. 1, 2020 in three hospitals (Zhonghan Hospital of Wuhan University (ZNWU), Leishenshan Hospital (LSS) and the Third Hospital of Hubei Province (HBTH)) of Wuhan, Hubei, China. A total of 240 patients with COVID-19 pneumonia were recruited from the three hospitals (120 from ZNWU, 88 from LSS, and 32 from HBTH). Patients receive either Favipiravir (1600mg, twice first day followed by 600mg, twice daily, for the following days) or Arbidol (200mg, three times daily) plus standard care for 7 days. The treatment could be extended to 10 days at judgement of the researchers. Standard care could comprise, as for the patient's best interest, traditional Chinese herbal medicine, antibiotics, additional antiviral treatment, immunomodulatory drugs, steroids, psychotic drugs, nutrition support, cardiovascular drugs, supportive oxygen, noninvasive positive pressure ventilation (NPPV) or invasive ventilation. Randomized open label (1:1 ratio between Arbidol and Favipiravir) was produced by professional statistical software SAS (version 9.4) and assigned to patients. The study was approved by the Institutional Ethics Committee (No. 2020040) (additional details in Protocol/SAP).

\section{Measurements}

Patients were assessed at the time of enrollment for basic physical parameters, body temperature, chronic viral co-infections, HCG (for childbearing age female), COVID-19 clinical classification, SPO2, chest CT, IL-6, blood biochemistry, urinalysis, coagulation function, C-reactive protein and SARS-CoV-2 nucleic acid (additional details in Protocol/SAP). Clinical classification of moderate, severe and 
critical COVID-19 patients were performed according to the Chinese guideline. ${ }^{11}$ After enrollment, blood biochemistry, urinalysis, coagulation function, C-reactive protein and SARS-CoV-2 nucleic acid were examined on the third (D3 \pm 1 day) and the seventh day (D7 \pm 2 day) with additional chest CT on the seventh day. The axillary temperature, respiratory rate, oxygen saturation without supportive oxygen, usage of oxygen therapy and noninvasive positive pressure ventilation (NPPV) were recorded in daily follow-up. Repeated measurements were made at least twice in each follow-up. The measurements were taken after 15 minutes rest at room temperature $\left(23 \pm 2^{\circ} \mathrm{C}\right)$. Adverse events and concomitant medication were observed.

\section{Outcome definitions}

The primary outcome was the clinical recovery rate at 7 days from the beginning of treatment. Clinical recovery was defined as continuous ( $>72$ hours) recovery of body temperature, respiratory rate, oxygen saturation and cough relief after treatment, with following quantitative criteria: axillary temperature $\leq 36.6^{\circ} \mathrm{C}$; respiratory frequency $\leq 24$ times/min; Oxygen saturation $\geq 98 \%$ without oxygen inhalation; mild or no cough. Secondary outcomes included the latency to pyrexia relief (for patients with pyrexia at the time of enrollment), the latency to cough relief (for patients with moderate or severe cough at the time of enrollment), the rate of AOT or NMV, all-cause mortality, dyspnea, rate of respiratory failure (defined as $\mathrm{SPO}_{2} \leq 90 \%$ without oxygen inhalation or $\mathrm{PaO}_{2} / \mathrm{FiO}_{2}<300 \mathrm{mmHg}$, requires oxygen therapy or additional respiratory support), and the rate of patients needed to receive intensive care in ICU. Safety outcomes 
included adverse events occurred during treatment and premature discontinuation.

\section{Statistical analysis}

With a limited knowledge of the efficacy for Arbidol, we assumed a 50\% clinical recovery rate at Day 7 for the Arbidol group. A superior clinically efficacy of Favipiravir was then expected to be at least $70 \%$. With $\alpha=0.025$ (single side), $\beta=0.20$, power $=0.80$ we estimated 92 participants was required for each group. The sample size increased about $20 \%$ considering shedding/elimination. Hence, the trial was designed to include 240 participants in the group, including 120 in the experimental group and 120 in the control group. SAS (v9.4) software was used for statistical analysis. For primary outcome (clinical recovery rate at Day 7), the comparison between the experimental group and the control group adopts the optimal test. Bilateral 95\% CI of the difference between the clinical recovery rate of the experimental group and the control group was calculated. If the lower limit was larger than 0 , it was considered the experimental group is superior to the control group. Log rank test was used to compare the recovery latency between the two groups. For secondary outcomes, student's T-test or Wilcoxon rank sum test (if T-test was not applicable) was performed for safety indicators and continuous variables, Wilcoxon rank sum test was used for grade variables. Frequency or composition (\%) were used for statistical description of categorial variables, and Chi-square test or Fisher's exact test was used for comparison between groups. For all statistical tests, $\mathrm{P}<0.05$ (bilateral) were considered as statistically significant. 


\section{Results}

\section{Clinical characteristics of patients}

A total of 240 patients with COVID-19 were enrolled, in which 236 took at least one dosage of drug were considered as the full analysis set (FAS) (Figure S1-S2). The FAS set includes 116 in the Favipiravir group and 120 in the Arbidol group (Table 1). In the Favipiravir group, 59 (50.86\%) were males and 57 (49.14\%) were females, 87 $(75.00 \%)$ were $<65$ years and $29(25.00 \%)$ were $\geq 65$ years, $36(31.03 \%)$ were with hypertension and $14(12.07 \%)$ with diabetes. In the Arbidol group, 51 (42.50\%) were males and $69(57.50 \%)$ were females, $79(65.83 \%)$ were <65 years and $41(34.17 \%)$ were $\geq 65$ years, $30(25.00 \%)$ were with hypertension and $13(10.83 \%)$ with diabetes. Main signs and symptoms for enrolled patients were pyrexia, fatigue, dry cough, myalgia, dyspnea, expectoration, sore throat, diarrhea, dizziness, insomnia and conjunctivitis, none of which were significantly different between groups. There was no difference between the time from onset of patient symptoms to time of treatment initiation between groups. Neither the SARS-CoV-2 nucleic acid tests, lymphocyte count, erythrocyte sedimentation rate and C-reactive protein differed between groups (Table 1). 116 cases in Favipiravir group and 119 in Arbidol group underwent chest CT, in which 112 (96.55\%) and 114 (95.80\%) were diagnosed COVID-19 pneumonia according to the diagnostic criteria $(\mathrm{P}=0.7635)$. Overall, no significant difference of basic characteristics of patients between the two groups was observed. However, we noticed a marginally increased ratio of severe to critical patients in the Favipiravir group (16 (severe)+2 (critical)) compared to Arbidol group (8+1) $(\mathrm{P}=0.0658$, Fisher's 
exact test, OR: 2.25 [0.91-5.98]).

\section{Comparison of clinical recovery rate of Day 7 of Favipiravir and Arbidol in}

\section{COVID-19 patients}

The group statistics of primary and secondary outcomes were presented in Table 2 and Table S1. At Day 7, 62/120 (51.67\%) in the Arbidol group and 71/116 (61.21\%) patients in the Favipiravir group $(\mathrm{P}=0.1396)$ were clinically recovered (difference of recovery rate (DRR): 0.0954, 95\% confidence interval (CI): -0.0305 0.2213) (Figure 2). Hence, we conclude that Favipiravir does not show superior efficacy compared to Arbidol in terms of improving the clinical recovery rate at Day 7.

Post-hoc test for interaction between treatment and clinical classification showed no interaction between these two factors, both of which contributed to the primary outcome $(\mathrm{P}=0.017$ for treatment, and $\mathrm{P}<0.001$ for clinical classification, with a general linear model). A post-hoc analysis found that for moderate patients with COVID-19, clinical recovery of Day 7 was 62/111 (55.86\%) in the Arbidol group and 70/98 $(71.43 \%)$ in the Favipiravir group ( $\mathrm{P}=0.0199)$ (DRR: 0.1557 , 95\% CI: $0.0271 \sim 0.2843)$; for severe/critical patients, clinical recovery rate was $0 / 9(0 \%)$ in the Arbidol group and 1/18 (5.56\%) in the Favipiravir group ( $\mathrm{P}=0.4712)$ (DRR: 0.0556, 95\% CI: $-0.0503 \sim 0.1614)$.

Comparison of duration of pyrexia, cough relief time and auxiliary oxygen therapy or noninvasive mechanical ventilation rate 
Table 3 displayed duration of pyrexia, cough relief time and auxiliary oxygen therapy or noninvasive mechanical ventilation rate between the Favipiravir and Arbidol groups. At baseline, for patients in Favipiravir group, 71/116 (61.2\%) had pyrexia and 78/116 (67.2\%) had cough; for patients in the Arbidol group, 74/120 (61.7\%) had pyrexia and 73/120 (60.8\%) had cough. Whilst the incidence of pyrexia and cough did not differ between two groups at baseline, both the latency to pyrexia reduction and cough relief in the Favipiravir group was significantly shorter than that in the Arbidol group $(\mathrm{P}<0.0001)$ (Figure 3).

The incidence of de novo auxiliary oxygen therapy (AOT) or noninvasive mechanical ventilation (NMV) was 27/120 (22.50\%) in the Arbidol group and 21/116 (18.10\%) in the Favipiravir group ( $\mathrm{P}=0.4015)$ (DRR: $-4.40 \%$, 95\% CI: $-14.64 \% \sim 5.85 \%)$. For all cases enrolled in this study, the all-cause mortality was 0 . The number of cases of respiratory failure were 4 in Arbidol group and 1 in Favipiravir group $(\mathrm{P}=0.3700)$. Patients with dyspnea was 15/120 (12.5\%) in the Arbidol group and 13/116 (11.2\%) in the Favipiravir group $(\mathrm{P}=0.7588)$. A post-hoc analysis showed that de novo incidences of dyspnea during the course of treatment occurred at 4/116 (3.45\%) patients in the Favipiravir group and 14/120 (11.67\%) patients in the Arbidol group $(\mathrm{P}=0.0174)$. Hence, we conclude that for secondary outcomes, Favipiravir significantly shortened the latency to relief for cough and pyrexia. Favipiravir was not associated with a decreased rate for AOT or NMV, dyspnea, overall respiratory failure rate, ICU admission or all-cause mortality. 


\section{Comparison of antiviral-associated adverse effects}

During this trial, we detected 37 incidences of antiviral-associated adverse effects (AE) in the Favipiravir group and 28 incidences in the Arbidol group. All observed AE incidences were level 1. Favipiravir was associated with increased serum uric acid (3 (2.50\%) in Arbidol group vs $16(13.79 \%)$ in Favipiravir group, $\mathrm{P}=0.0014)$. No statistical difference was observed for the frequency of abnormal ALT/AST, psychiatric symptom reactions or digestive tract reactions (Table 4). Most of these adverse reactions disappeared by the time patients being discharged. 


\section{Discussion}

We conducted a prospective, multicenter, open-labeled, randomized superiority clinical trial and hypothesized that Favipiravir would be superior to Arbidol in terms of efficacy for moderate symptoms, and would accelerate the clinical recovery of pyrexia, cough, and breathing difficulties compared with Arbidol.

Favipiravir treatment did not improve clinical recovery rate of Day 7 (61.21\%) compared to Arbidol group (51.67\%). However, it did significantly improve the latency to cough relief and decreased the duration of pyrexia. Favipiravir was not associated with any differences in ICU admission, AOT/NMV, dyspnea, respiratory failure or all-cause mortality.

Interestingly, post-hoc observation showed that a trend of Favipiravir being effective to improve clinical recovery rate at Day 7 in moderate COVID-19 patients compared to Arbidol. This effect diminished for severe/critical COVID-19 patients. Additionally, post-hoc analysis showed that for moderate COVID-19 patients, Favipiravir was associated with decreased auxiliary oxygen therapy or noninvasive mechanical ventilation rate with marginal significance $(\mathrm{P}=0.0541)$. Finally, in the FAS, post-hoc analysis also showed that Favipiravir treatment significantly decreased de novo incidences of dyspnea. Whether Favipiravir would be only effective for moderate COVID-19 patients, or could Favipiravir be used to prevent disease progression, is a question warrant future investigation.

The combination of traditional Chinese medicine and antiviral drugs is more common in China, which is due to the traditional medical culture background of the treatment 
of choice. Also, anti-infection and immune regulation play an important role in the treatment of the COVID-19. Ancillary treatments, such as traditional Chinese medicine, anti-infection and immunomodulatory drugs, were without statistical difference between groups (Table S2).

Our trial has several limitations. Firstly, for COVID-19, there is no clinically proven effective antiviral drug to serve as the control arm. Although Chinese guideline had recommended several options including Arbidol, ${ }^{11}$ no RCT results on these drugs were reported. Arbidol was widely used by Chinese doctors in the beginning stage of this epidemic of COVID-19 (Jan. 1-30, 2020) based on in vitro evidence. ${ }^{12}$ For ethical reasons, we chose Arbidol for the control arm. Secondly, observation time frame was limited due to the urgency of this epidemic. For the same reason, no relapse (including nucleic acid conversion, pyrexia, cough, or pneumonia progress by radiology) tracking were performed for the discharged patients. Thirdly, in the inclusion criteria, we did not force positive nucleic acid test as a necessity. The accuracy of nucleic acid assay was limited, which might due to multiple reasons including previous treatment, latency of onset, sampling method, biological specimen characteristics. This particular accuracy problem was a known issue among clinical practitioners across the world. It was estimated that the assay might have at most $30 \%-50 \%$ of sensitivity for patients in early stage of the disease, whilst contact history, clinical manifestations, radiology evidences, and lab results including leukopenia and lymphopenia could be confirmatory for these nucleic-acid-negative pneumonia patients. In the Chinese guideline, ${ }^{11}$ patients meeting these criteria were considered as 
with clinically confirmed COVID-19. In this trial, $46.55 \%$ patients in Favipiravir group and $38.33 \%$ in Arbidol group were nucleic-acid-positive at enrollment. Considering the population incidence of COVID-19 infection at the time of this trial in Wuhan, we consider the probability for mis-identifying patients of pneumonia disease other than COVID-19 into this trial is low. Fourthly, the protocol does not prespecify clinical classification as a stratification factor. Ethical concerns arose against completely excluding severe/critical cases from potential beneficial treatment. Additionally, because of the complexity of the disease, progression from moderate to severe/critical is possible. Terminating trial treatment to such patients from the study was considered unacceptable. Post-hoc analysis showed that both treatment and clinical classification contributed significantly to the primary outcome of clinical recovery rate at Day 7. Difference of the frequency of severe/critical patients between groups reached a marginal significance, which made an important impact on the trial outcome. 
medRxiv preprint doi: https://doi.org/10.1101/2020.03.17.20037432; this version posted April 15, 2020. The copyright holder for this preprint (which was not certified by peer review) is the author/funder, who has granted medRxiv a license to display the preprint in perpetuity.

All rights reserved. No reuse allowed without permission.

\section{Conclusions}

Compared to Arbidol, Favipiravir does not significantly improve clinical recovery rate of Day 7. Favipiravir is associated with significantly shortened latency to relief for pyrexia and cough. Antiviral-associated adverse effects of Favipiravir are mild and manageable. 


\section{Funding and disclosures}

This work was supported by the National Key Research and Development Program of China (2020YFC0844400). The funder had no role in the design and conduct of the study; collection, management, analysis, and interpretation of the data; preparation, review, or approval of the manuscript; and decision to submit the manuscript for publication. All authors have no conflicts of interest to declare.

We would like to acknowledge the support of China National Center for Biotechnology Development, Science and Technology Department of Hubei Province. We thank the excellent technical assistance of Dr. Xiuli Zhao (Beijing Tongren Hospital, Capital Medical University, Beijing, China). We also thank the help from the rescue medical teams for Hubei province (Tianjin medical team, Liaoning medical team, Guangdong Province Traditional Chinese Medical Hospital, Longhua Hospital Shanghai University of Traditional Chinese Medicine, Liyuan Hospital of Tongji Medical College of Huazhong University of Science and Technology, and Puren Hospital of Wuhan University of Science and Technology). 


\section{References}

1. Coronavirus Disease (COVID-19) - Statistics and Research. https://ourworldindata.org/coronavirus. 2020.

2. Coronavirus disease 2019 (COVID-19) Situation Report. https://www.who.int/. 2020 .

3. Dong L, Hu S, Gao J. Discovering drugs to treat coronavirus disease 2019 (COVID-19). Drug Discov Ther 2020;14:58-60.

4. Wang D, Hu B, Hu C, et al. Clinical Characteristics of 138 Hospitalized Patients With 2019 Novel Coronavirus-Infected Pneumonia in Wuhan, China. JAMA 2020; doi: 10.1001/jama.2020.1585.

5. Pshenichnaya NY, Bulgakova VA, Lvov NI, et al. Clinical efficacy of umifenovir in influenza and ARVI (study ARBITR). Ter Arkh 2019;91:56-63.

6. Hulseberg CE, Feneant L, Szymanska-de Wijs KM, et al. Arbidol and Other Low-Molecular-Weight Drugs That Inhibit Lassa and Ebola Viruses. J Virol 2019;93(8):e02185-18.

7. Shi L, Xiong H, He J, et al. Antiviral activity of arbidol against influenza A virus, respiratory syncytial virus, rhinovirus, coxsackie virus and adenovirus in vitro and in vivo. Arch Virol 2007;152:1447-55.

8. Goldhill DH, Te Velthuis AJW, Fletcher RA, et al. The mechanism of resistance to favipiravir in influenza. Proc Natl Acad Sci U S A 2018;115:11613-8.

9. Furuta Y, Takahashi K, Fukuda Y, et al. In vitro and in vivo activities of anti-influenza virus compound T-705. Antimicrob Agents Chemother 2002;46:977-81. 10. Chinese diagnosis and treatment plan of COVID-19 patients (The fifth edition). http://www.nhc.gov.cn/yzygj/s7653p/202002/3b09b894ac9b4204a79db5b8912d4440. shtml. 2020.

11. Chinese diagnosis and treatment plan of COVID-19 patients (The sixth edition). http://www.nhc.gov.cn/yzygj/s7653p/202002/8334a8326dd94d329df351d7da8aefc2.s html. 2020.

12. Li Q, Guan X, Wu P, et al. Early Transmission Dynamics in Wuhan, China, of Novel Coronavirus-Infected Pneumonia. N Engl J Med 2020;382(13):1199-1207. 
Table 1. Basic characteristics of the participants.

\begin{tabular}{|c|c|c|c|}
\hline Variables & $\begin{array}{l}\text { Favipiravir group } \\
\qquad(\mathrm{N}=116)\end{array}$ & $\begin{array}{l}\text { Arbidol group } \\
(\mathrm{N}=\mathbf{1 2 0})\end{array}$ & $P$ value \\
\hline Gender, n (\%) & & & 0.2473 \\
\hline Female & $57(49.14)$ & $69(57.50)$ & \\
\hline Male & $59(50.86)$ & $51(42.50)$ & \\
\hline Age (years), n (\%) & & & 0.1232 \\
\hline$<65$ & $87(75.00)$ & $79(65.83)$ & \\
\hline$\geq 65$ & $29(25.00)$ & $41(34.17)$ & \\
\hline Clinical Classification, $\mathrm{n}(\%)$ & & & 0.1540 \\
\hline Moderate & $98(84.48)$ & $111(92.50)$ & \\
\hline Severe & $16(13.79)$ & $8(6.67)$ & \\
\hline Critical & $2(1.72)$ & $1(0.83)$ & \\
\hline Hypertension, n (\%) & $36(31.03)$ & $30(25.00)$ & 0.3018 \\
\hline Diabetes, n (\%) & $14(12.07)$ & $13(10.83)$ & 0.7656 \\
\hline Insomnia, n (\%) & $16(13.79)$ & 29 (24.17) & 0.0426 \\
\hline Conjunctivitis, n (\%) & $6(5.17)$ & $7(5.83)$ & $1.0000^{*}$ \\
\hline \multicolumn{4}{|l|}{ Signs and symptoms, n (\%) } \\
\hline Pyrexia & $64(55.17)$ & $61(50.83)$ & 0.5911 \\
\hline Fatigue & $40(34.48)$ & $27(22.50)$ & 0.0579 \\
\hline Dry cough & $70(60.34)$ & $64(53.33)$ & 0.3393 \\
\hline Myalgia & $2(1.72)$ & $3(2.50)$ & $1.0000^{*}$ \\
\hline Dyspnea & $9(7.76)$ & $4(3.33)$ & 0.2285 \\
\hline Expectoration & $13(11.21)$ & $11(9.17)$ & 0.7619 \\
\hline Sore throat & $9(7.76)$ & $17(14.17)$ & 0.1726 \\
\hline Diarrhea & $22(18.97)$ & $15(12.50)$ & 0.2354 \\
\hline Dizziness & $1(0.86)$ & $5(4.17)$ & 0.2306 \\
\hline \multicolumn{4}{|l|}{ Laboratory findings } \\
\hline Nucleic acid tests, n (\%) & $\mathrm{N}=116$ & $\mathrm{~N}=120$ & 0.4202 \\
\hline Positive & $54(46.55)$ & $46(38.33)$ & \\
\hline Suspected & $6(5.17)$ & $6(5.00)$ & \\
\hline Lymphocyte count, $\times 10^{9} / \mathrm{L}$ & $\mathrm{N}=116$ & $\mathrm{~N}=120$ & 0.5316 \\
\hline Mean (SD) & $0.95(0.25)$ & $0.97(0.34)$ & \\
\hline Min-Max & $0.54-2.14$ & $0.36-2.21$ & \\
\hline Erythrocyte sedimentation rate (ESR) & $\mathrm{N}=114$ & $\mathrm{~N}=120$ & 0.9498 \\
\hline Mean (SD) & $17.24(14.34)$ & $17.34(10.76)$ & \\
\hline Min-Max & $2.00-96.00$ & $2.00-61.00$ & \\
\hline C-reactive protein (CRP) & $\mathrm{N}=116$ & $\mathrm{~N}=118$ & 0.4796 \\
\hline Mean (SD) & $10.91(21.55)$ & $9.19(14.92)$ & \\
\hline Min-Max & $0.50-212.60$ & $0.50-111.90$ & \\
\hline Chest CT (N = 235 with data), n (\%) & 116 & 119 & 0.7635 \\
\hline
\end{tabular}


medRxiv preprint doi: https://doi.org/10.1101/2020.03.17.20037432; this version posted April 15, 2020. The copyright holder for this preprint (which was not certified by peer review) is the author/funder, who has granted medRxiv a license to display the preprint in perpetuity.

All rights reserved. No reuse allowed without permission.

\section{COVID-19 pneumonia}

$112(96.55)$

$114(95.80)$

"T-test was performed for continuous variables, frequency or composition (\%) were used for statistical description of classification indexes, and Chi-square test or Fisher's exact test was used for comparison between groups. 
medRxiv preprint doi: https://doi.org/10.1101/2020.03.17.20037432; this version posted April 15, 2020. The copyright holder for this preprint (which was not certified by peer review) is the author/funder, who has granted medRxiv a license to display the preprint in perpetuity.

All rights reserved. No reuse allowed without permission.

Table 2. Comparison of clinical recovery rate of Day 7.

\begin{tabular}{ccccc}
\hline Variables & Favipiravir group & Arbidol group & Rate ratio (95\% CI) & P value \\
\hline Total patients & $(\mathbf{N}=\mathbf{1 1 6})$ & $(\mathbf{N}=\mathbf{1 2 0})$ & & 0.1396 \\
Recovered, n (\%) & $71(61.21)$ & $62(51.67)$ & $0.0954(-0.0305,0.2213)$ & \\
Moderate patients & $(\mathbf{N}=\mathbf{9 8})$ & $(\mathbf{N}=\mathbf{1 1 1})$ & & \\
Recovered, n (\%) & $70(71.43)$ & $62(55.86)$ & $0.1557(0.0271,0.2843)$ & 0.0199 \\
Severe or critical patients & $\mathbf{( N = 1 8 )}$ & $(\mathbf{N}=\mathbf{9})$ & & \\
Recovered, n (\%) & $1(5.56)$ & $0(0.00)$ & $0.0556(-0.0503,0.1614)$ & 0.4712 \\
Patients with hypertension and/or diabetes & $(\mathbf{N}=\mathbf{4 2})$ & $(\mathbf{N}=\mathbf{3 5})$ & & \\
Recovered, $n(\%)$ & $23(54.76)$ & $18(51.43)$ & $0.0333(-0.1904,0.2571)$ & 0.7704 \\
\hline
\end{tabular}


Table 3. Comparison of time to relief for pyrexia, cough relief time and other secondary outcomes.

\begin{tabular}{|c|c|c|c|c|}
\hline \multirow[t]{2}{*}{ Variables } & \multicolumn{2}{|c|}{ Time to relief for pyrexia } & \multicolumn{2}{|c|}{ Cough relief time } \\
\hline & Favipiravir group & Arbidol group & Favipiravir group & Arbidol group \\
\hline Total patients & $(N=71)$ & $(N=74)$ & $(\mathrm{N}=78)$ & $(N=73)$ \\
\hline Day 1 & $15(21.13)$ & $2(2.70)$ & $1(1.28)$ & $3(4.11)$ \\
\hline Day 2 & $23(32.39)$ & $8(10.81)$ & $2(2.56)$ & $1(1.37)$ \\
\hline Day 3 & $19(26.76)$ & $18(24.32)$ & $23(29.49)$ & $7(9.59)$ \\
\hline Day 4 & $10(14.08)$ & $15(20.27)$ & $20(25.64)$ & $11(15.07)$ \\
\hline Day 5 & $1(1.41)$ & $16(21.62)$ & $10(12.82)$ & $12(16.44)$ \\
\hline Day 6 & - & $5(6.76)$ & $10(12.82)$ & $10(13.70)$ \\
\hline Day 7 & - & $3(4.05)$ & $3(3.85)$ & $3(4.11)$ \\
\hline Day 8 & - & - & $7(8.97)$ & $6(8.22)$ \\
\hline Day 9 & - & - & $1(1.28)$ & $3(4.11)$ \\
\hline Censored & - & - & $1(1.28)$ & $17(23.29)$ \\
\hline Log-rank $P$ value & \multicolumn{2}{|c|}{$<0.0001$} & \multicolumn{2}{|c|}{$<0.0001$} \\
\hline \multicolumn{5}{|c|}{ Other secondary outcomes } \\
\hline AOT or $\mathrm{NMV}^{*}$ & Favipiravir group & Arbidol group & Rate ratio $(95 \% \mathrm{CI})$ & $P$ value \\
\hline Total patients & $\mathrm{N}=116$ & $\mathrm{~N}=120$ & & \\
\hline With auxiliary, n (\%) & $21(18.10)$ & $27(22.50)$ & $-0.0440(-0.1464,-0.0585)$ & 0.4015 \\
\hline Patients with hypertension and/or diabetes & $\mathrm{N}=42$ & $\mathrm{~N}=35$ & & \\
\hline With auxiliary, n (\%) & $9(21.43)$ & $10(28.57)$ & $-0.0714(-0.2658,0.1230)$ & 0.4691 \\
\hline All-cause mortality & $0(0.00)$ & $0(0.00)$ & l & / \\
\hline Dyspnea after taking medicine, n (\%) & $4(3.45)$ & $14(11.67)$ & l & 0.0174 \\
\hline Respiratory failure, $n(\%)$ & $1(0.86)$ & $4(3.33)$ & l & $0.3700^{*}$ \\
\hline
\end{tabular}


"Fisher's exact test was used for comparison between groups.

AOT: Auxiliary oxygen therapy.

NMV: Noninvasive mechanical ventilation. 
medRxiv preprint doi: https://doi.org/10.1101/2020.03.17.20037432; this version posted April 15, 2020. The copyright holder for this preprint (which was not certified by peer review) is the author/funder, who has granted medRxiv a license to display the preprint in perpetuity.

All rights reserved. No reuse allowed without permission.

Table 4. Comparison of antiviral-associated adverse effects.

\begin{tabular}{cccccc}
\hline \multirow{2}{*}{ Adverse effects } & \multicolumn{2}{c}{ Favipiravir group $(\mathbf{N}=\mathbf{1 1 6})$} & \multicolumn{2}{c}{ Arbidol group $(\mathbf{N}=\mathbf{1 2 0})$} & \multirow{2}{*}{ P value } \\
\cline { 2 - 5 } & Frequency & Cases, $\mathbf{n}(\%)$ & Frequency & Cases, $\mathbf{n}(\%)$ & \\
\hline Total & 43 & $37(31.90)$ & 33 & $28(23.33)$ & 0.1410 \\
Abnormal LFT & 10 & $10(8.62)$ & 12 & $12(10.00)$ & 0.7156 \\
Raised serum uric acid & 16 & $16(13.79)$ & 3 & $3(2.50)$ & 0.0014 \\
Psychiatric symptom reactions & 5 & $5(4.31)$ & 1 & $1(0.83)$ & $0.1149^{*}$ \\
Digestive tract reactions & 16 & $16(13.79)$ & 17 & $14(11.67)$ & 0.6239 \\
\hline
\end{tabular}

*Fisher's exact test was used for comparison between groups. 
medRxiv preprint doi: https://doi.org/10.1101/2020.03.17.20037432; this version posted April 15, 2020. The copyright holder for this preprint (which was not certified by peer review) is the author/funder, who has granted medRxiv a license to display the preprint in perpetuity. All rights reserved. No reuse allowed without permission.

\section{Figure legend}

Figure 1. Flow diagram of the study.

Figure 2. Time to clinical recovery in the trial population.

Figure 3. Time to (A) pyrexia or (B) cough relief in the trial population. 


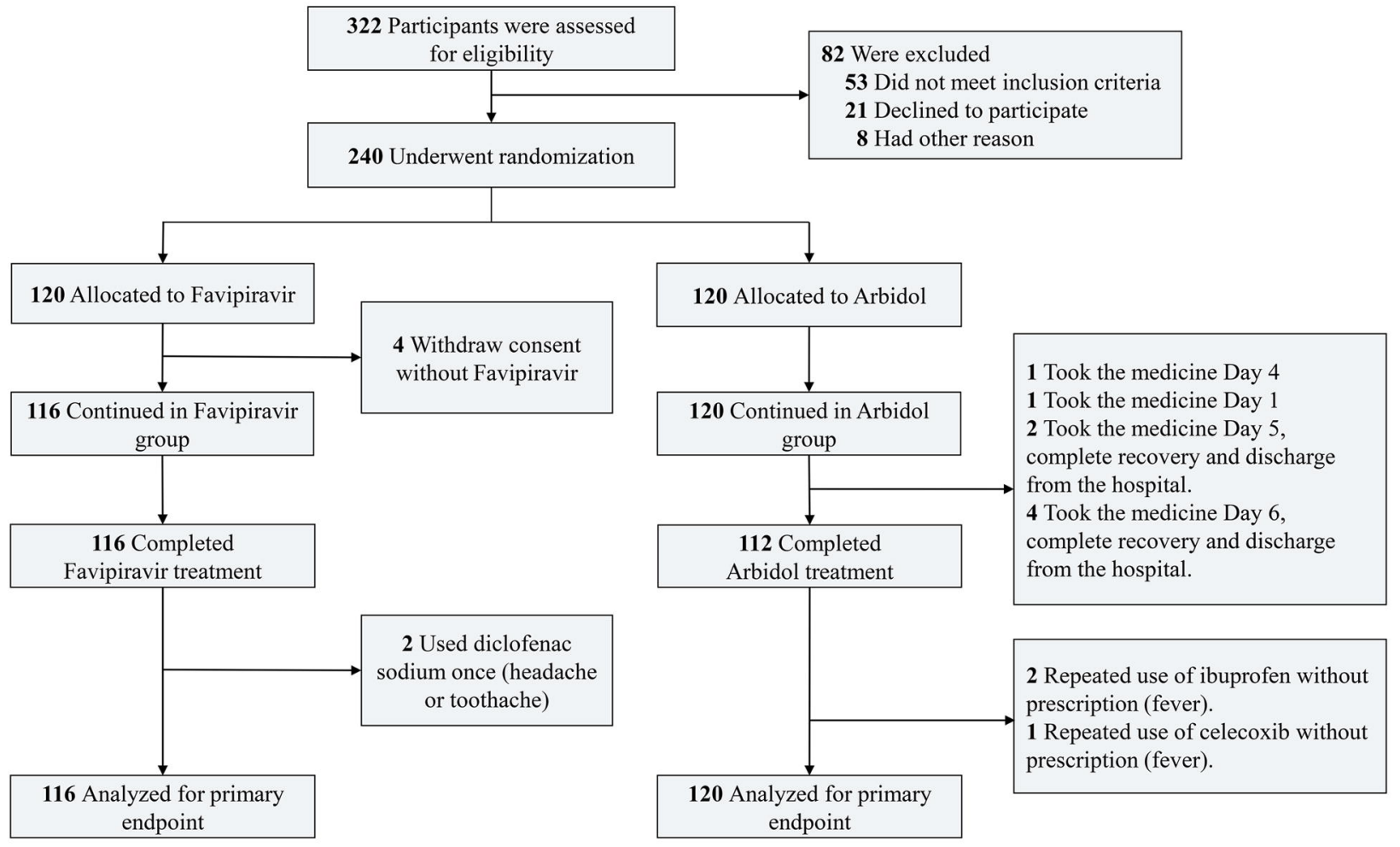




\section{Time to clinical recovery}

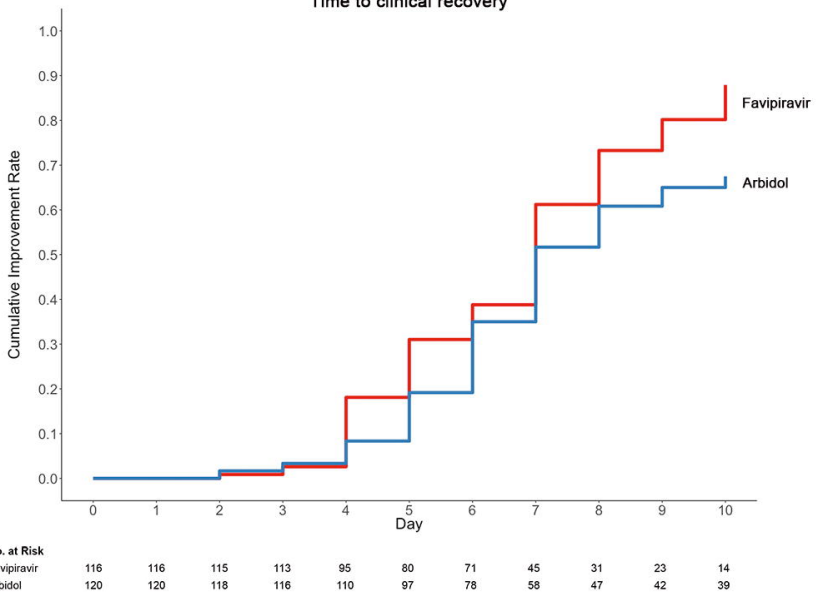




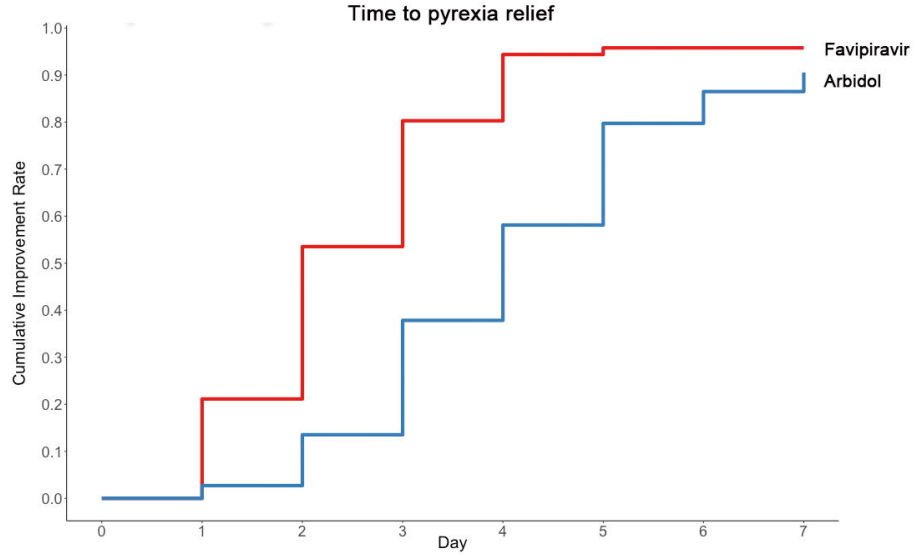

No. at Risk

Favipiravir

Arbidol

$71 \quad 56$

74
33
64
14

46
4
31

31

3
15

15

3

10
3

7

B

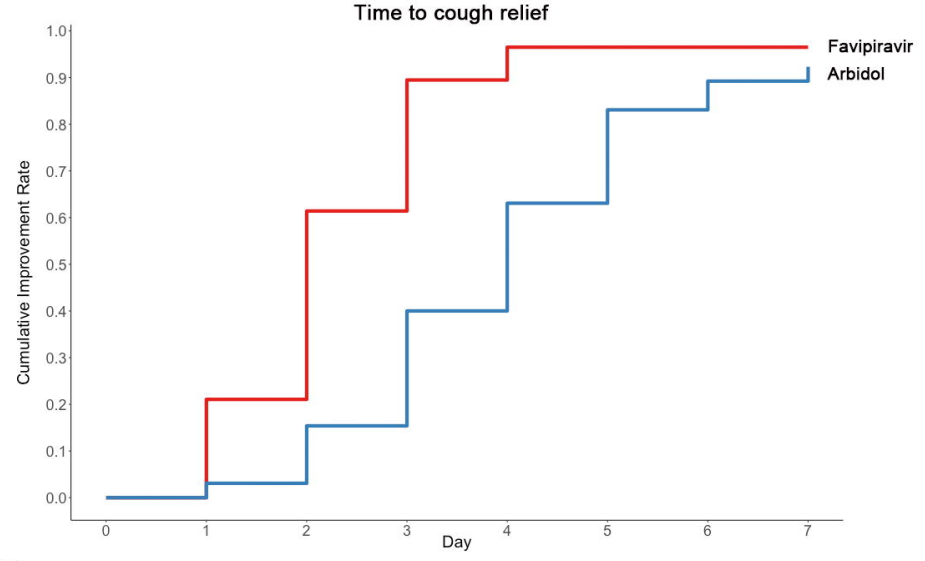

No. at Risk

Favipiravir

Arbidol
57

65
45

63
22

55
6

39
2

24
2

11
2

7
2

5 